\title{
Translation and cross-cultural adaptation of the Venous Leg Ulcer Self Efficacy Tool for use in a Swiss-French setting
}

Venous leg ulcers are lesions between the ankle joint and the knee caused by chronic venous insufficiency. The Venous Leg Ulcer Self Efficacy Tool (VeLUSET) was developed to measure self-care and self-efficacy in Englishspeaking persons with venous leg ulcers. This study describes the translation and cross-cultural adaptation of the original version of the VeLUSET from English into Swiss French.

Keywords:
venous leg ulcers; translation; cross-cultural adaptation; self-efficacy

\section{ABSTRACT}

Background

Venous leg ulcers are slow-healing wounds.

\section{Objective}

The aim of this study was to translate and crossculturally adapt the original version of Venous Leg Ulcer Self Efficacy Tool (VeLUSET) from English into Swiss French.

\section{Method/Results}

A cross-cultural research study in three outpatient clinics in western Switzerland was conducted following $^{1}$ translation of the original instrument into Swiss French by two independent translators, ${ }^{2}$ construction of a consensus version based on both translations, ${ }^{3}$ two independent back translations of the consensus version into English, ${ }^{4}$ review by an expert committee and construction of a draft questionnaire, ${ }^{5}$ testing of the draft questionnaire on people with a venous leg ulcer and ${ }^{6}$ construction of the final questionnaire version.

\section{Conclusion}

This process of translation and cultural adaptation produced a new version of the VeLUSET for validation and later use among the French-speaking population of Switzerland. An upcoming separate study will investigate the psychometric properties of the adapted questionnaire in the new setting.

\section{Implication for clinical practice}

People in different settings have different cultural norms, literacy levels and beliefs and might thus respond differently to clinical tools. The implication for clinical practice is that a translated clinical tool, such as the VeLUSET questionnaire, might not measure the same concepts in different cultural settings. When using clinical tools, clinicians need to consider the origin of development and testing of the tool and whether cultural expectations, literacy levels or beliefs impact responses and thus the interpretation of the results of the tool.

${ }^{1}$ La Source, HES-SO University of Applied Sciences and Arts Western Switzerland, Lausanne, Switzerland.

${ }^{2}$ Epidemiology, Biostatistics and Prevention Institute, University of Zurich, Zurich, Switzerland.

${ }^{3}$ Geneva School of Health Sciences, HES-SO University of Applied Sciences and Arts Western Switzerland, Geneva, Switzerland. 


\section{Key messages}

- The seven-step method of Sousa and Rojjanasrirat provided an accepted best practice structure for translating the English version of the VeLUSET into Swiss French.

- Further, the translated VeLUSET_FR was culturally adapted for the Swiss French setting.

- The translated and adapted version of the VeLUSET questionnaire is ready for validation to establish whether it can be used to measure the self-care of Swiss French venous ulcer patients.

\section{INTRODUCTION}

Venous leg ulcers (VLUs) are lesions between the ankle joint and the knee caused by chronic venous insufficiency. The occurrence ranges between 0.8 and 2.2 per 1000 people/year. ${ }^{1}$ Healing times of VLUs are long, and up to $70 \%$ of the patients suffer a recurrence within three months after wound closure..$^{2-4}$
These wounds have a negative impact on all aspects of daily life. ${ }^{5-8}$

Current therapeutic approaches for VLUs focus on wound healing and on preventive measures such as wearing compression stockings, performing leg and ankle exercises, leg elevation and a balanced diet. ${ }^{4,9-}$

${ }^{11}$ However, adherence to therapeutic recommendations is poor and thought to be due to insufficient knowledge. ${ }^{12-13}$ This knowledge deficit is related to a low level of self-care and self-efficacy. ${ }^{9-11}$ Evidence demonstrates that self-efficacy is a facilitator in the adoption of self-care, which is important in preventing the recurrence of ulcers. ${ }^{14-15}$ Based on this sociocognitive theory, it can be deduced that the ability to adapt behaviour can first be quantified by measuring self-efficacy and second be influenced by targeting self-efficacy. ${ }^{14,16}$ Currently, only one instrument to measure self-efficacy in the VLU population has been developed and validated, the Venous Leg Ulcer Self Efficacy Tool (VeLUSET). ${ }^{16}$ This English-language tool consists of general statements about wearing

Table 1. Study Phases and Steps

Steps Sousa and Rojjanasrirat

$1 \quad$ Forward translated to the target language (TL)

Idem by two independent translators

2 Comparison of the two translations and discussion

of the discrepancies of the preliminary initial translated

version of the instrument in the target language (PI-TL)

3 Blind back translation of the PI-TL by two inde-

Adapted pendent translators

4 Comparison of the two back-translated versions of the instrument (B-TL1 and B-TL2)

5 Pilot testing of the draft version of the instrument in the target language (P-FTL), sampling Separate study ${ }^{18}$

10-40 individuals with 'with questions that are clear and not dichotomous"Conceptual equivalence (clarity) evaluated by 6-10 members of an expert panel.

6 Preliminary psychometric testing of the P-FTL with

Not undertaken a bilingual sample 
compression stockings (5 items) and of affirmations about daily self-care tasks (16 items) with which people can agree (or not) on a scale from 0 (total disagreement) to 10 (total agreement). Mean scores for each item can be compared. Its internal reliability as assessed with Cronbach's $\alpha$ is $0.931 .{ }^{16}$

This study is the first of two phases of a methodological study. The aims of the first phase are the translation and cross-cultural adaptation of the original English VeLUSET into Swiss French, based on the seven-step methodology of Sousa and Rojjanasrirat. ${ }^{17}$

\section{METHOD}

This study describes the translation and cross-cultural adaptation of the original version of the VeLUSET from English into Swiss French. The second step of the validation of the instrument, the assessment of the psychometric properties of the translated version, is described elsewhere. ${ }^{18}$

\section{Instrument}

The original version of the VeLUSET was developed to measure self-care and self-efficacy in Englishspeaking persons with VLU. The tool assesses 30 items on a self-reporting basis. The items assess the 5 dimensions of self-efficacy for persons with VLU: conducting general self-care ( 5 items), daily self-care tasks (12 items), normal living (4 items), developing expertise (6 items) and avoiding trauma (3 items).
The scale was developed using a focus group approach of persons with VLU. The items were written in the form of statements based on self-efficacy findings. This formulation assessed a person's understanding of the aetiology of his or her ulcer and provides the latest recommendations on self-care to be adopted. The scale ranges between 0 (totally disagree) and 10 (totally agree). The reported Cronbach's $\alpha$ of the total scale has been reported as 0.931 and 0.834 , with $0.851,0.753,0.828$ and 0.804 for the subscales, respectively. The assessed test-retest reliability over a four-week interval was excellent $(\mathrm{r}=0.92 ; \mathrm{n}=20$; $\mathrm{P}<0.001) .{ }^{16}$

\section{Translation process}

The accepted method of instrument translation and cultural adaptation suggested by Sousa and Rojjanasrirat was adapted using four of their seven steps (see figure 1) that are applicable to the context of this study. Additionally, an expert committee was consulted; it focused on the technicality of the instrument and the precision of the terms to be translated. ${ }^{17}$ All experts concurrently considered the content, semantic, technical, criterion and conceptual equivalence of the tool. Step six of the pilot test was not done due to the non-availability of bilingual participants, while the seventh step of psychometric testing was conducted in a separate study and is described elsewhere. ${ }^{18}$

\section{Table 2. Translation process - an example}

\section{Original English Version $\quad$ Forward translation}

Translator 1:

Je suis convaincu de ce qui suit: je comprends pourquoi je dois porter les bas de contention pour le restant de I am confident that:
I understand why I
need to wear my
compression stockings
for the rest of my life.

$$
\text { mes jours. }
$$

\section{Translator 2:}

J'ai confiance dans le fait que: je comprends pourquoi j'aurais besoin de mettre mes bas de compression pour le restant de ma vie

Backward translation Draft version

Translator 3:

I have confidence in the fact

that: I understand why I will

need to wear my

compression stockings for

the rest of my life.

\section{Translator 4:}

I am confident that: I understand why I will need to put my compression stockings for the rest of my life.
J'ai confiance que: je comprends pourquoi je dois porter les bas de compression pour le restant de mes jours. 


\section{RESULTS}

The translation process is outlined in the following description of the four steps described by Sousa and Rojjanasrirat. ${ }^{17}$ Four (French and English) bilingual experts with similar academic backgrounds - three PhD holders with a health science background and a translator unfamiliar with medical terminology carried out the translation blindly and independently. Two experts independently forward translated the instrument from the original language to the target language. As a second step, two other experts back translated the translated version into the original language. The four translators and the first and last authors of this article then compared the two backtranslated versions with the original version, and a consensus version was elaborated. The example in Table 2 illustrates the process.

\section{DISCUSSION}

The aim of this study was to translate and crossculturally adapt the original version of the VeLUSET from English into Swiss French using an adapted version of the accepted method of Sousa and Rojjanasrirat. ${ }^{17}$ This adaptation was crucial to responding to the specific circumstances of the setting and to ensure a coherent methodology. ${ }^{17}$ It is essential that the literal meaning of a word be translated, along with its relationship to the context. ${ }^{19}$ This is important because some terms or concepts used in health care language do not exist in other languages. Evidence shows people from different cultural backgrounds respond differently to clinical tools. ${ }^{20}$

\section{Conclusion and recommendation for practice}

The translation and cultural adaptation of the VeLUSET questionnaire from an English-speaking setting to a French-speaking setting in Switzerland will now allow for the assessment of psychometric properties.

\section{REFERENCES}

1. Berenguer Pérez M, López-Casanova P, Sarabia Lavín R, González de la Torre H, Verdú-Soriano J. Epidemiology of venous leg ulcers in primary health care: Incidence and prevalence in a health centre-A time series study (2010-2014). Int Wound J. 2019 Feb; 16(1):256-65.

2. Abbade LPF, Lastoria $S$, de Almeida Rollo H, Ometto Stolf H. A sociodemographic, clinical study of patients with venous ulcer. Int J Dermatol. 2005 Dec; 44(12):989 92.

3. McDaniel HB, Marston WA, Farber MA, Mendes RR, Owens LV, Young ML, et al. Recurrence of chronic venous ulcers on the basis of clinical, etiologic, anatomic, and pathophysiologic criteria and air plethysmography. J Vasc Surg. 2002 Apr; 35(4):723 8.

4. Finlayson K, Wu M-L, Edwards HE. Identifying risk factors and protective factors for venous leg ulcer recurrence using a theoretical approach: A longitudinal study. Int J Nurs Stud. 2015 Jun; 52(6):1042 51.

5. Green J, Jester R. Health-related quality of life and chronic venous leg ulceration: Part 1 . Br J Community Nurs. 20091 Dec; 14(6):12 7.

6. Green J, Jester R, McKinley R, Pooler A. Patien perspectives of their leg ulcer journey. J Wound Care. $2013 \mathrm{Feb} ; 22(2): 5866$

7. Green J, Jester R, McKinley R, Pooler A. The impact of chronic venous leg ulcers: A systematic review. J Wound Care. 20142 Dec; 23(12):601 12.
8. Guarnera G, Tinelli G, Abeni D, Di Pietro C, Sampogna F, Tabolli S. Pain and quality of life in patients with vascular leg ulcers: An Italian multicentre study. J Wound Care. 2007 Aug: 16(8):347 51

9. Finlayson K, Edwards H, Courtney M. Factors associated with recurrence of venous leg ulcers: A survey and retrospective chart review. Int J Nurs Stud. 2009 Aug; 46(8):1071 8.

10. Finlayson K, Edwards H, Courtney M. Relationships between preventive activities, psychosocial factors and recurrence of venous leg ulcers: A prospective study. J Adv Nurs. 2011 Oct; 67(10):2180 90.

11. Brown A. Self-care strategies to prevent venous leg ulceration recurrence. Pract Nurs. 2018 Apr; 29(4):152 8.

12. Finlayson K, Edwards H, Courtney M. The impact of psychosocial factors on adherence to compression therapy to prevent recurrence of venous leg ulcers. J Clin Nurs. 2010 May; 19(9 10):1289 97.

13. Van Hecke A, Grypdonck M, Beele H, Vanderwee K, Defloor T. Adherence to leg ulcer lifestyle advice: Qualitative and quantitative outcomes associated with a nurse-led intervention. J Clin Nurs. 2011 Feb; 20(3/4):429 43.

14. Bandura A. Self-efficacy mechanism in human agency. Am Psychol. 1982; 37(2):122 47.
15. Richard AA, Shea K. Delineation of self-care and associated concepts: Self-care concept delineation. J Nurs Scholarsh. 2011 Jul; 43(3):255-64.

16. Brown A, Kendall S, Flanagan M, Cottee M. Encouraging patients to self-care-The preliminary development and validation of the VeLUSET(C), a self-efficacy tool for venous leg ulcer patients, aged 60 years and over. Int Wound J. 2014 Jun; 11(3):326 34.

17. Sousa VD, Rojjanasrirat W. Translation, adaptation and validation of instruments or scales for use in cross-cultural health care research: a clear and user-friendly guideline: Validation of instruments or scales. J Eval Clin Pract. 2011 Apr; 17(2):268 74.

18. Probst $S$, Turcotte M, Buehrer Skinner M. Internal consistency and reliability of the Swiss-French translation of the Venous Leg Ulcer Self Efficacy tool (VeLUSET). BMJ Open. 2019 Dec; 9(12):e031529.

19. Esposito N. From meaning to meaning: The influence of translation techniques on non-English focus group research. Qual Health Res. 2001 Jul; 11(4):568-79.

20. Dunckley M, Hughes R, Addington-Hall JM, Higginson IJ. Translating clinical tools in nursing practice. J Adv Nurs. 2003 Nov; 44(4):420-6. 